07.3

\title{
Перовскитный солнечный элемент с дырочным транспортным слоем на основе комплекса полианилина
}

\author{
() О.Д. Якобсон ${ }^{1}$, О.Л. Грибкова ${ }^{1}$, А.Р. Тамеев ${ }^{1,2}$, Е.И. Теруков ${ }^{3,4}$ \\ ${ }^{1}$ Институт фоизической химии и электрохимии им. А.Н. Фрумкина РАН, Москва, Россия \\ ${ }^{2}$ Национальный исследовательский университет „Высшая школа экономики“, Москва \\ ${ }^{3}$ Санкт-Петербургский государственный электротехнический университет „ЛЭТИ“, Санкт-Петербург, Россия \\ ${ }^{4}$ НТЦ тонкопленочных технологий в энергетике при Физико-техническом институте им. А.Ф. Иоффе РАН, \\ Санкт-Петербург, Россия \\ E-mail: iakobson.olga@yandex.ru
}

Поступило в Редакцию 6 мая 2019г.

В окончательной редакции 6 мая 2019г.

Принято к публикации 7 мая 2019г.

\begin{abstract}
Впервые разработаны перовскитные солнечные элементы с фотоактивным слоем из иодида метиламмония свинца и дырочно-транспортным слоем на основе комплекса полианилина с поли-2-акриламидо-2-метил1-пропансульфоновой кислотой. Эффективность фотопреобразования полученных устройств соответствует известным мировым аналогам. По результатам моделирования оптических параметров ячейки в рамках модели Максвелла-Гарнета установлено, что наблюдаемая экспериментально слабая зависимость КПД фотопреобразования устройства от толщины слоя перовскита в диапазоне $350-500 \mathrm{~nm}$ связана с отсутствием заметного изменения как количества поглощенной фотоактивным слоем энергии, так и темпа генерации экситонов.
\end{abstract}

Ключевые слова: перовскиты, солнечные элементы, полианилин, моделирование.

DOI: 10.21883/PJTF.2019.16.48145.17866

В настоящее время идут активные разработки солнечных элементов (СЭ), включающих в качестве фотоактивного материала металлоорганические соединения со структурой перовскита (галогениды метиламмония или формамидиния свинца или олова) [1,2]. Применение таких соединений не только позволяет приблизить эффективность работы устройств на их основе к эффективности работы традиционных кремниевых СЭ, но и дает возможность создавать легкие, недорогие и гибкие пленочные устройства с помощью нетрудоемких технологий (термонапыление в вакууме, полив из раствора, печать).

Важную роль в структуре СЭ играют зарядотранспортные слои, повышающие эффективный сбор электронов и дырок на соответствующих электродах [3]. Наиболее распространенным материалом для дырочно-транспортного слоя (ДТС) органических СЭ является водорастворимый комплекс поли-3,4-этилендиокситиофена с полистиролсульфонатом [4]. Присущие этому комплексу недостатки (образование твердой фазы в дисперсии при хранении, относительно высокая кислотность, гигроскопичность слоя [3]) делают актуальным поиск новых полимерных материалов для ДТС.

Недавно нами было показано, что комплекс полианилина с поли-2-акриламидо-2-метил-1-пропансульфоновой кислотой (ПАНИ-ПАМПСК), который характеризуется достаточным уровнем проводимости [5,6], стабильностью электрических и оптических свойств в течение двух лет и более [7], может быть успешно применен в качестве транспортных слоев устройств органической электроники, в частности дырочно-транспортных слоев органических СЭ с объемным гетеропереходом [8]. В то же время в перовскитных солнечных элементах (ПСЭ) с фотоактивным слоем (ФС) на основе органо-неорганических соединений перовскитной структуры (например, иодида метиламмония свинца $\left.\left(\mathrm{MAPbI}_{3}\right)\right)$ подобные комплексы полианилина (ПАНИ) применялись редко. Примером могут служить данные работы [9], в которой в качестве ДТС была использована пленка комплекса ПАНИ с полистиролсульфокислотой (ПССК), а также многокомпонентная система на его основе с добавлением поверхностно-активных веществ, и данные [10], где использовался привитый сополимер ПАНИ и ПССК.

В настоящей работе был применен ДТС на основе комплекса ПАНИ-ПАМПСК при создании ПСЭ с фотоактивным слоем из иодида метиламмония свинца $\mathrm{MAPbI}_{3}$ и определен диапазон оптимальной толщины $\mathrm{MAPbI}_{3}$. При этом экспериментальные характеристики ПСЭ с учетом толщины $\mathrm{MAPbI}_{3}$ были сопоставлены

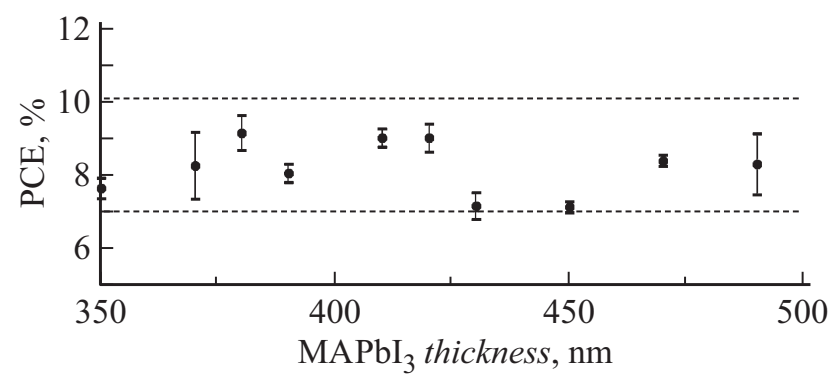

Рис. 1. Зависимость КПД фотопреобразования ПСЭ от толщины ФС. 


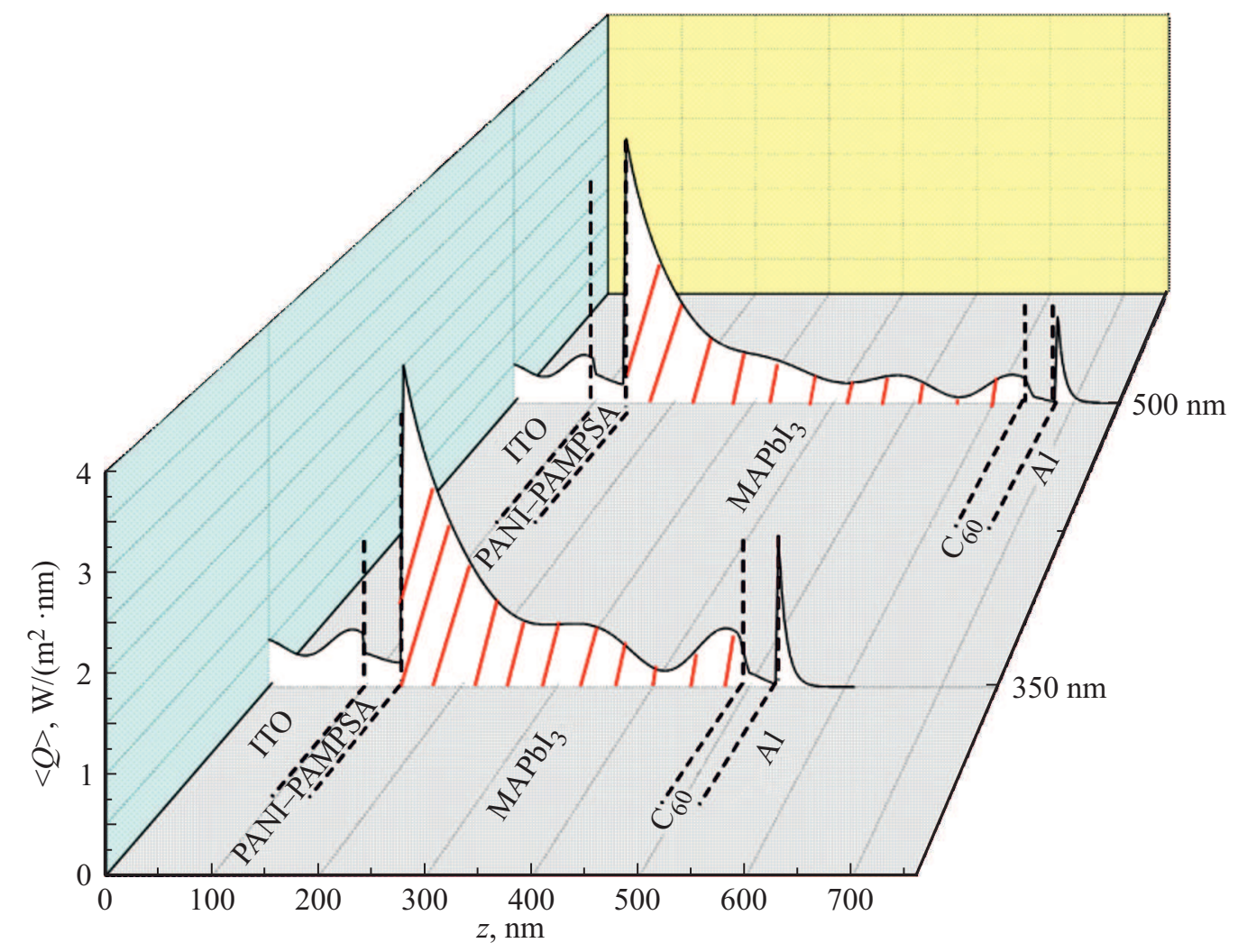

Рис. 2. Зависимость поглощенной энергии в приборе от координаты для ПСЭ с ФС толщиной 350 и $500 \mathrm{~nm}$.

с результатами моделирования оптических параметров ПСЭ в рамках модели Максвелла-Гарнета.

Комплексы ПАНИ-ПАМПСК были приготовлены по описанной ранее методике [11]. Тонкие пленки комплекса ПАНИ-ПАМПСК были получены методом полива из дисперсии на стеклянную прозрачную подложку, покрытую проводящим слоем смеси оксидов индия и олова (ITO), с последующим отжигом $\left(70^{\circ} \mathrm{C}\right)$ в атмосфере аргона в течение $10 \mathrm{~min}$. Слой перовскита наносился методом центрифугирования $(5000 \mathrm{rpm}, 30 \mathrm{~s})$, для чего были использованы $90 \mu \mathrm{l}$ $\mathrm{N}, \mathrm{N}$-диметилформамида, содержащего $1.5 \mathrm{M}$ метиламмония иодида $\left(\mathrm{CH}_{3} \mathrm{NH}_{3} \mathrm{I}\right.$, Dyesol) и $1.5 \mathrm{M}$ иодида свинца $\left(\mathrm{PbI}_{2}\right.$, AlfaAesar). Слой перовскита $\mathrm{MAPbI}_{3}$ формировался способом, описанным нами ранее [12]. Электронтранспортный слой фуллерена $\mathrm{C}_{60}$, блокирующий слой 2,9-диметил-4,7-дифенил-1,10-фенантролина (ВСР), и электрод Al были нанесены методом вакуумного термического напыления. Образцы ПСЭ имели структуру ITO $(100 \mathrm{~nm}) /$ ПАНИ-ПАМПСК $(40 \mathrm{~nm}) / \mathrm{MAPbI}_{3}$ (изменяемой толщины) $/ \mathrm{C}_{60}(40 \mathrm{~nm}) / \mathrm{BCP}(7 \mathrm{~nm}) / \mathrm{Al}(80 \mathrm{~nm})$.

Ряд публикаций указывает на зависимость эффективности работы ПСЭ от толщины перовскитного слоя $[13,14]$. В связи с этим в настоящей работе было изучено влияние толщины слоя перовскита на рабочие характеристики ПСЭ.

На рис. 1 приведены усредненные значения КПД фотопреобразования для полученных ПСЭ с ФС на основе иодида метиламмония свинца перовскитной структуры, толщина которого изменялась в диапазоне $350-500 \mathrm{~nm}$.

Видно, что изменение толщины перовскитного слоя в диапазоне $350-500 \mathrm{~nm}$ не оказывает существенного влияния на эффективность работы ПСЭ: для всех устройств КПД варьировался в диапазоне 7-10\%. Следует отметить, что полученные значения КПД фотопреобразования сопоставимы с данными, описанными в литературе для устройств ПСЭ с ДТС на основе ПАНИ-ПССК и привитого сополимера ПАНИ-ПССК, не модифицированных добавками $[9,10]$.

Для расчета оптических характеристик многослойных структур ПСЭ использовался метод матриц переноса, разработанный Хэвенсом (Heavens) и впервые примененный для органических солнечных элементов Петтерссоном (Pettersson). В теории матриц переноса свет рассматривается как плоская волна, причем для фотоэлектрических устройств рассматривается только свет при нормальном падении на подложку. Распространение электрического поля через каждый слой описывается матрицей $2 \times 2$. При этом каждый слой многослойного устройства описывается своим комплексным показателем преломления $\left(n=n^{\prime}+i k\right)$ и толщиной. Более подробное описание теории приведено в [15]. При моделировании оптических свойств ПСЭ с ФС из иодида метиламмония свинца и ДТС на основе комплекса ПАНИ-ПАМПСК в качестве исходных данных были использованы полученные экспериментально методом эллипсометрии оптические константы (показатель пре- 
Темп генерации экситонов в зависимости от толщины ФС

\begin{tabular}{c|c}
\hline $\begin{array}{c}\text { Толщина } \Phi С, \\
\mathrm{~nm}\end{array}$ & $\begin{array}{c}\text { Темп генерации экситонов } \\
\text { в активном слое, } \\
10^{-16} \mathrm{~cm}^{-2} \cdot \mathrm{s}^{-1}\end{array}$ \\
\hline 350 & 9.6 \\
370 & 9.5 \\
400 & 9.4 \\
450 & 9.4 \\
500 & 9.9
\end{tabular}

ломления $n^{\prime}$ и коэффициент экстинкции $k$ ) для пленки ПАНИ-ПАМПСК, слоя ITO и слоя $\mathrm{MAPbI}_{3}$, а также литературные данные для остальных слоев устройства: для $\mathrm{C}_{60}[16]$ и слоя $\mathrm{Al}[17]$. Рассмотренный спектральный диапазон лежал от 360 до $800 \mathrm{~nm}$.

На рис. 2 представлена типичная зависимость поглощенной энергии в приборе от координаты для ПСЭ с ФС толщиной 350 и $500 \mathrm{~nm}$. Видно, что с ростом толщины ФС практически отсутствует увеличение количества поглощенной энергии (наблюдается сглаживание максимумов поглощения с ростом толщины ФС), прирост интеграла поглощенной энергии для пленки толщиной $500 \mathrm{~nm}$ составляет только $3.5 \%$ по сравнению с таковым для пленки толщиной $350 \mathrm{~nm}$. При этом при прохождении через толстые слои в реальных устройствах увеличивается вероятность потерь разделенных зарядов.

Результаты моделирования темпа генерации экситонов в активном слое ПСЭ представлены в таблице.

Как видно из таблицы, расчеты указывают на слабую зависимость темпа генерации экситонов в ФС от его толщины.

Таким образом, установлено, что толщина слоя перовскита $\mathrm{MAPbI}_{3}$ в диапазоне $350-500 \mathrm{~nm}$ слабо (коэффициент вариации составляет $8.44 \%$ ) влияет на эффективность работы ПСЭ. Моделирование ПСЭ позволило выявить, что это связано с отсутствием заметного изменения как количества поглощенной фотоактивным слоем энергии, так и темпа генерации экситонов в $\mathrm{MAPbI}_{3}$ с ростом его толщины.

\section{Благодарности}

Авторы благодарят Р.Ш. Ихсанова (НИУ ВШЭ) за ценные замечания по моделированию оптических параметров солнечных элементов.

\section{Финансирование работы}

Исследование выполнено при финансовой поддержке Российского фонда фундаментальных исследований (проект № 18-29-23045) и Министерства науки и высшего образования РФ (оборудование). А.Р. Тамеев также выполнил часть исследования по моделированию в рамках Программы фундаментальных исследований Национального исследовательского университета „Высшая школа экономики“.

\section{Конфликт интересов}

Авторы заявляют, что у них нет конфликта интересов.

\section{Список литературы}

[1] Zhao Z., Gu F., Rao H., Ye S., Liu Z., Bian Z., Huang C. // Adv. Energy Mater. 2019. V. 9. N 3. P. 1802671.

[2] Torabi N., Behjat A., Zhou Y., Docampo P., Stoddard R.J., Hillhouse H.W., Ameri T. // Mater. Today Energy. 2019. V. 12. P. 70-94.

[3] Po R., Carbonera C., Bernardi A., Camaioni N. // Energy Environ. Sci. 2011. V. 4. N 2. P. 285-310.

[4] Mehmood U., Al-Ahmed A., Hussein I.A. // Renew. Sustain. Energy Rev. 2016. V. 57. P. 550-561.

[5] Омельченко О.Д., Грибкова О.Л., Тамеев А.Р., Ванников А.В. // Письма в ЖТФ. 2014. Т. 40. В. 18. С. 66-71.

[6] Iakobson O.D., Gribkova O.L., Tameev A.R., Kravchenko V.V., Egorov A.V., Vannikov A.V. // Synth. Met. 2016. V. 211. P. 8998.

[7] Якобсон О.Д., Грибкова О.Л., Некрасов А.А., Тверской В.А., Иванов В.Ф., Мельников П.В., Поленов Е.А., Ванников А.В. // Физикохимия поверхности и защита материалов. 2016. Т. 52. № 6. С. 613-620.

[8] Iakobson O.D., Gribkova O.L., Tameev A.R., Nekrasov A.A., Saranin D.S., Di Carlo A. // J. Ind. Eng. Chem. 2018. V. 65. P. 309-317.

[9] Lee K., Cho K.H., Ryu J., Yun J., Yu H., Lee J., Na W., Jang J. // Electrochim. Acta. 2017. V. 224. P. 600-607.

[10] Lim K.-G., Ahn S., Kim H., Choi M.-R., Huh D.H., Lee T.-W. // Adv. Mater. Interfaces. 2016. V. 3. N 9. P. 1500678.

[11] Gribkova O.L, Nekrasov A.A., Trchova M., Ivanov V.F., Sazikov V.I., Razova A.B., Tverskoy V.A., Vannikov A.V. // Polymer. 2011. V. 52. N 12. P. 2474-2484.

[12] Saranin D.S., Mazov V.N., Luchnikov L.O., Lypenko D.A., Gostishev P.A., Muratov D.S., Podgorny D.A., Migunov D.M., Didenko S.I., Orlova M.N., Kuznetsov D.V., Tameev A.R., Di Carlo A. // J. Mater. Chem. C. 2018. V. 6. N 23. P. 61796186.

[13] Wang K., Liu C., Du P., Chen L., Zhu J., Karim A., Gong X. // Org. Electron. 2015. V. 21. P. 19-26.

[14] Liu D., Gangishetty M.K., Kelly T.L. // J. Mater. Chem. A. 2014. V. 2. N 46. P. 19873-19881.

[15] Sievers D.W., Shrotriya V., Yang Y. // J. Appl. Phys. 2006. V. 100. N 11. P. 114509.

[16] Milani P., Manfredini M., Guizzetti G., Marabelli F., Patrini M. // Solid State Commun. 1994. V. 90. N 10. P. 639642.

[17] McPeak K.M., Jayanti S.V., Kress S.J.P., Meyer S., Iotti S., Rossinelli A., Norris D.J. // ACS Photon. 2015. V. 2. N 3. P. 326-333. 